Research Paper

\title{
Microbial biofilm composition and polymer degradation of compostable and non-compostable plastics immersed in the marine environment
}

\author{
Alice Delacuvellerie $^{\mathrm{a}, *}$, Samira Benali ${ }^{\mathrm{b}}$, Valentine Cyriaque ${ }^{\mathrm{a}}$, Sébastien Moins ${ }^{\mathrm{b}}$, \\ Jean-Marie Raquez ${ }^{\mathrm{b}}$, Sylvie Gobert ${ }^{\mathrm{c}}$, Ruddy Wattiez ${ }^{\mathrm{a}}$ \\ a Proteomics and Microbiology Department, University of Mons, 20 place du parc, 7000 Mons, Belgium \\ ${ }^{\mathrm{b}}$ Polymer and Composite Materials Department, University of Mons, 15 Avenue Maistriau, 7000 Mons, Belgium \\ ${ }^{\mathrm{c}}$ Oceanology Department, University of Liège, 11 Allée du 6 août, 4000 Liège, Belgium
}

\section{A R T I C L E I N F O}

\section{Editor: Dr. G. Jianhua}

\section{Keywords:}

Plastisphere

Enrichment culture

Bacterial community

Sequencing

Mediterranean Sea

\begin{abstract}
A B S T R A C T
Different plastic types considered as compostable are found on the market such as petro-based (e.g., polybutylene adipate terephthalate (PBAT)) or bio-based plastics (e.g., polylactic acid, (PLA)). Even if their degradation has been confirmed in industrial compost conditions, investigation of their degradation in natural marine environment has been limited. To better understand biodegradation into natural marine environment, commercial compostable (PBAT, semi-crystalline and amorphous PLA) and non-compostable polymers (low density polyethylene, polystyrene, polyethylene terephthalate, polyvinyl chloride) were submerged in situ on the sediment and in the water column in the Mediterranean Sea. These samples were studied by chemical and microbiological approaches. After 82 days of immersion, no significant bacterial degradation of the different polymers was observed, except some abiotic alterations of PBAT and LDPE probably due to a photooxidation process. However, after 80 days in an enrichment culture containing plastic films as a main carbon source, Marinomonas genus was specifically selected on the PBAT and a weight loss of $12 \%$ was highlighted. A better understanding of the bacterial community colonizing these plastics is essential for an eco-design of new biodegradable polymers to allow a rapid degradation in aquatic environment.
\end{abstract}

\section{Introduction}

Due to their iniquitousness and predominant role in our daily lives, petroleum-based plastics production increases every year. In 2015, nine percent of their global production was recycled while seventy-nine percent of the discarded plastics ended up in landfills or in oceans (Geyer et al., 2017). Single-use plastics such as plastic bags and microbeads are a dominant pollution source (Xanthos and Walker, 2017). The most widely used non-biodegradable plastic in Europe are low density polyethylene (LDPE), polystyrene (PS), polyethylene terephthalate (PET) and polyvinyl chloride (PVC) (Plastics, 2019). Once entered in the marine environment, plastics debris were ingested by the fauna (e.g., whales, seabirds, turtles, seals, etc.) and cause the death of hundreds of thousand animals (Rochman et al., 2013a, 2013b; Wilcox et al., 2015) provoking a global ecological impact.

To avoid this global issue, compostable polymers such as polylactic acid (PLA) and polybutylene adipate terephthalate (PBAT) are considered a solution to pollution issues and now replace some single use nonbiodegradable plastics. Indeed, these plastic types have a perdurability limited in the environment. In 2018, around 912,000 tons of these plastics were produced. The PLA, one of the world's best-selling bioplastics considered as an excellent alternative to PP (polypropylene) and

Abbreviations: FTIR, Fourier transform infrared spectroscopy; ATR, using the attenuated total reflectance; $\bigoplus_{\mathrm{M}}$, Dispersity; DSC, differential scanning calorimetry; FP, plastic in the water column; LDPE, low density polyethylene; $\mathrm{M}_{\mathrm{n}}$, number average molecular weight; $\mathrm{M}_{\mathrm{W}}$, Mass average molar mass; NA, not applicable; nbGLM, negative binomial distribution and Generalized Linear Model; nMDS, non-metric multidimensional scaling; OUT, operational taxonomic unit; PBAT, polybutylene adipate terephthalate; PET, polyethylene terephthalate; PHBV, poly(3-hydroxybutyrate-co-3-hydroxyvalerate; PLA, polylactic acid; PP, polypropylene; PS, polystyrene; PVC, polyvinyl chloride; RG, response group; SEC, size exclusion chromatography; SP, plastic on sediment; $\mathrm{T}_{\mathrm{C}}$, cold crystallization temperature; $\mathrm{T}_{\mathrm{g}}$, glass transition temperature; $\mathrm{t}_{\mathrm{i}}$, initial time; $\mathrm{T}_{\mathrm{M}}$, melting temperature; UV, ultraviolet; $\mathrm{X}_{\mathrm{c}}$, crystallinity; $\Delta \mathrm{H}_{\mathrm{c}}$, cold crystallization enthalpy; $\Delta H_{m}$, melting crystallization enthalpy.

* Corresponding author.

E-mail address: alice.delacuvellerie@umons.ac.be (A. Delacuvellerie). 
PS represents $24 \%$ of the biodegradable plastic production while PBAT, equivalent to LDPE, represents $17 \%$ of this production (Bioplastics Market Data Report, 2018). The PLA is a biobased plastic as this polymer is produced by the bacterial fermentation of agricultural byproducts rich in carbohydrate at a large industrial scale while the PBAT is a petro-based polymer.

The biodegradation process involves two important factors: (1) the action of the physicochemical parameters (abiotic degradation) and (2) the microbial activity (biotic degradation) (Haider et al., 2019). Temperature is an important parameter for biodegradation in compost. Indeed, a temperature close to the glass transition temperature of the polymer $\left(58{ }^{\circ} \mathrm{C}\right.$ for amorphous PLA and $62{ }^{\circ} \mathrm{C}$ for semi-crystallin PLA) facilitates the degradation. These two polymers are considered as compostable under anaerobic conditions as they are degraded up to $90 \%$ into $\mathrm{CO}_{2}$ in compost at $70{ }^{\circ} \mathrm{C}$ after 180 days (ISO 14855), in anaerobic conditions. However, their degradation outside of these controlled conditions, in aerobic conditions and in the presence of new microorganisms such as in natural marine environments, is unknown. Recent studies tested the degradation capacity of different biodegradable polymers, including PLA, in managed and unmanaged conditions. They showed that PLA is not biodegradable either in home composts or in reactors mimicking marine environments (Naranci et al., 2018). No evidence of bacterial degradation was observed in dynamic or static seawater after 10 weeks of immersion (Karamanlioglu et al., 2017). Finally, Beltran-Sanahuja et al. (2020) compared the PLA blends degradation into different seawater compartment in cylinders simulating water conditions (euphotic zone, aphotic zone, in non-polluted sediment and in organic polluted sediment) showing that the compartment influences the degradation of PLA with a higher degradation into the non-polluted sediment with a weight loss of $75.3 \%$ after 365 days. In the sediment, Accinelli et al. (2012), showed that the amount of bacteria was higher than in the water column and that the bacterial community has a role in the plastic degradation.

In the biotic degradation step of compostable plastics, microbial communities developing on these polymer surface have an important role. Plastic residues entering in the marine environment are rapidly colonized and composes a distinct ecological niche named the "plastisphere" (Zettler et al., 2013). This niche is colonised by different microorganisms such as diatoms, fungi and bacteria. In this framework, several studies have described the microbial communities able to colonise non-biodegradable plastics showing that the composition of the bacterial communities evolves gradually with the immersion time of the polymer: (i) Alphaproteobacteria and Gammaproteobacteria represent the primary colonizers of the plastic surface and (ii) Bacteroidetes constitute the secondary colonizers (De Tender et al., 2017a, 2017b). In addition, the bacterial community composition is linked to the sample position (floating plastics $v s$ plastics on the sediments) (Delacuvellerie et al., 2019). The colonisation of PHBV (poly(3-hydroxybutyrate-co-3-hydroxyvalerate) was monitored in an aquarium in natural sea water during 6 weeks, showing that the colonization density is higher on these plastics than on the non-biodegradable ones (Dussud et al., 2018) but the bacterial colonization profile of the biodegradable plastics was not described.

To better understand the behaviour of some compostable plastics in the natural marine environments and their colonisation by the bacterial communities, we immersed compostable and non-compostable plastics for 82 days in the Mediterranean Sea either on the sediment or in the water column. We combined chemical and genomic approaches to describe the bacterial community developing on compostable and noncompostable plastics and we tested the degradation efficiency of immersed plastics. A better understanding of this system is important to (i) eco-design new polymers with optimizing properties for the bacterial development and the biodegradation processes and (ii) develop realistic standard tests to evaluate the biodegradability of these polymers. Finally, we performed enrichment cultures in an attempt to select potential candidates that degrade compostable plastics (semi-crystalline
PLA, amorphous PLA and PBAT) and assess the involvement of specific bacteria in the plastic biodegradation.

\section{Materials and methods}

\subsection{Materials}

Three types of plastics were considered during this study: (Fig. S1): (i) non-compostable petro-based plastics (i.e., PET, PS, LDPE and PVC); (ii) compostable petro-based plastic (PBAT) and (iii) compostable biobased plastics (amorphous and semi-crystalline PLA). Non- compostable films were supplied by Goodfellow (c) and their characteristics are available in Table 1 .

The compostable plastics were provided as pellets (Table 2). The PBAT was supplied by BASF society and distributed by B-Plast 2000 (product code: Ecoflex F Blend C 1200). The semi-crystalline PLA (Ingeo $^{\mathrm{TM}} 4032 \mathrm{D}$ ) and the amorphous PLA (Ingeo ${ }^{\mathrm{TM}} 4060 \mathrm{D}$ ) were provided by Nature Works (USA).

Throughout the manuscript, we use the terms "plastic type" to differentiate compostable and non-compostable plastics.

\subsection{Preparation of compostable plastic films}

Before the film processing, the PLA and PBAT pellets were dried overnight. The films were pressed using a Carver 3851-0 hot-press machine (Wabash, U.S.A.) to obtain films of $5 \mathrm{~cm}$ diameter and 200 $\mu \mathrm{m}$ tick. The plate temperature was set at $150{ }^{\circ} \mathrm{C}$ and $200{ }^{\circ} \mathrm{C}$ for the PBAT and the PLA, respectively. The PBAT and the PLA were melted during $3 \mathrm{~min}$ and $5 \mathrm{~min}$, respectively before undergoing 2 degassing steps. After a pressure of 250 bar for $5 \mathrm{~min}$, the films were cooled down at room temperature for $5 \mathrm{~min}$ using water circulation within the plates of the pressure.

\subsection{Design of the environmental marine immersion experiments}

Plastic films were placed in-situ (salinity: 38 and pH: 8) in front of the marine station "STARESO" $\left(42.579741^{\circ} \mathrm{N}, 8.724418^{\circ} \mathrm{E}\right.$, Calvi, Corsica) (Fig. S2). Four replicates of each of the seven chemical composition of polymer were fixed on a plastic frame to avoid metal contamination (Fig. 1). The placement of the films was as follows: (i) in the water column at $4.5 \mathrm{~m}$ of depth and (ii) on the sediment at $8 \mathrm{~m}$ depth (on a sandy patch in the Posidonia oceanica meadow). The plastic frame was held in the water column between a weight placed on the bottom and a subsurface buoy. The second frame was placed and fixed on the sediment in the bottom with stakes made with concrete bars molded in PVC tubes. The polymers of different chemical compositions were alternately fixed on the frames and immersed during 82 days from May, 14 to August 5, 2019. After sampling, plastics were stored in sea water at $4{ }^{\circ} \mathrm{C}$. The microbial biofilms were delicately detached for 16S rRNA gene sequencing and the plastics were cleaned to perform their chemical characterization. The average sea surface temperature was $20.8{ }^{\circ} \mathrm{C}$

Table 1

Characteristics of the non-biodegradable plastic films.

\begin{tabular}{|c|c|c|c|c|c|}
\hline $\begin{array}{l}\text { Plastic } \\
\text { type }\end{array}$ & Thickness $^{\mathrm{a}}$ & Density $^{1}$ & $\begin{array}{l}\text { Melting } \\
\text { temperature }\end{array}$ & $\begin{array}{l}\text { Glass } \\
\text { transition } \\
\text { temperature }\end{array}$ & Crystallinity \\
\hline LDPE & $200 \mu \mathrm{m}$ & $\begin{array}{l}0.95 \mathrm{~g} / \\
\mathrm{cm}^{3}\end{array}$ & $109^{\circ} \mathrm{C}$ & $45^{\circ} \mathrm{C}$ & $40 \%$ \\
\hline PET & $200 \mu \mathrm{m}$ & $\begin{array}{l}1.3-1.4 \\
\mathrm{~g} / \mathrm{cm}^{3}\end{array}$ & / & $94{ }^{\circ} \mathrm{C}$ & Amorphous \\
\hline PVC & $200 \mu \mathrm{m}$ & $\begin{array}{l}1.4 \mathrm{~g} / \\
\mathrm{cm}^{3}\end{array}$ & / & $76^{\circ} \mathrm{C}$ & Amorphous \\
\hline PS & $125 \mu \mathrm{m}$ & $\begin{array}{l}1.05 \mathrm{~g} / \\
\mathrm{cm}^{3}\end{array}$ & / & $106^{\circ} \mathrm{C}$ & Amorphous \\
\hline
\end{tabular}

${ }^{a}$ Technical data provided by the supplier 
Table 2

Characteristics of biodegradable plastic pellets.

\begin{tabular}{lllll}
\hline $\begin{array}{l}\text { Plastic } \\
\text { type }\end{array}$ & Density & $\begin{array}{l}\text { Melting } \\
\text { temperature }\end{array}$ & $\begin{array}{l}\text { Glass transition } \\
\text { temperature }\end{array}$ & Crystallinity \\
\hline PBAT & $\begin{array}{l}1.26 \mathrm{~g} / \\
\mathrm{cm}^{3}\end{array}$ & $-29{ }^{\circ} \mathrm{C}$ & $120{ }^{\circ} \mathrm{C}$ & $13 \%$ \\
PLA & $\begin{array}{l}1.24 \mathrm{~g} / \\
\mathrm{cm}^{3}\end{array}$ & $58{ }^{\circ} \mathrm{C}$ & $/$ & Amorphous \\
$\begin{array}{c}\text { (4060D) } \\
\text { PLA }\end{array}$ & $\begin{array}{l}1.24 \mathrm{~g} / \\
\mathrm{cm}^{3}\end{array}$ & $62{ }^{\circ} \mathrm{C}$ & $166{ }^{\circ} \mathrm{C}$ & $4 \%$ \\
(4032D) & & & \\
\hline
\end{tabular}

(Rapid Assessment of the Coastal Environment, ULiège). The water mean temperature during the plastic immersion at a depth of $3 \mathrm{~m}$ was $20.8^{\circ} \mathrm{C}$.

\subsection{Chemical characterization}

Chemical characterisation was performed on all plastic films before and after immersion in the marine environment. Before characterization, the films were rinsed with ethanol $70 \%(\mathrm{~V} / \mathrm{V})$ and deionized water to remove organic coatings and dried at $30{ }^{\circ} \mathrm{C}$ for one day. The biofilms were removed from the immersed plastics and were analyzed for their bacterial communities.

We analysed the physicochemical properties to follow the abiotic degradation (polymer degradation by the action of physicochemical condition of the environment) with different relevant techniques: weight loss (Fig. 3), SEC (Table 3), DSC (Table 4), ATR-FTIR (Benali et al., 2015; Weng et al., 2013). As a reminder, ATR-FTIR allows to observe the surface groups of the polymer, in case of degradation, new peak corresponding to oxidative function appears. Glass transition temperature and crystallinity were followed by DSC, if the polymer is degraded, the $\mathrm{T}_{g}$ decreases and the crystallinity increases. Finally, parameters of chains constituting the polymer matrix such as $\mathrm{Mn}$ and $\mathrm{Ð}_{\mathrm{M}}$ were studied by the SEC analysis mainly for compostable plastic whose matrix is hydrolytically unstable.

\subsubsection{Weight loss method}

After drying, the plastic films were weighed and the percentage of weight loss was determined as follows (Roy et al., 2008):

Weight $\operatorname{loss}(\%)=\frac{\left(m_{i}-m_{f}\right)}{m_{i}} \times 100$

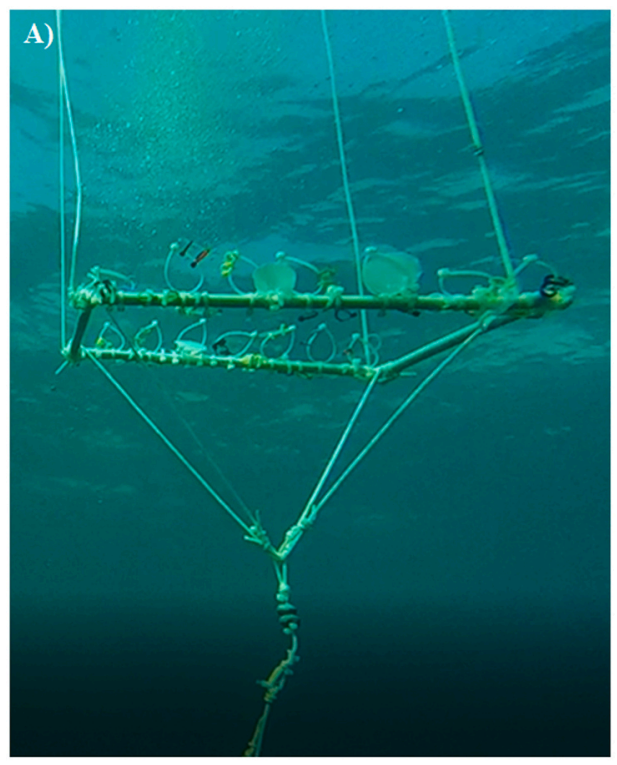

where $m_{i}$ is the weight of the plastic at the initial time and $m_{f}$, the weight after the immersion time.

\subsubsection{Differential scanning calorimetry (DSC)}

The DSC analyses were performed with a DSC Q2000 from TA Instruments ${ }^{\circledR}$, New Castle, USA. Temperature and enthalpy calibrations were performed using an indium standard. Around 5-7 mg of samples were sealed in aluminum standard pans. Samples were heated from -20.0 to $200{ }^{\circ} \mathrm{C}$ for the PLA and $-80-200{ }^{\circ} \mathrm{C}$ for the other polymers with a heating ramp of $10^{\circ} \mathrm{C} / \mathrm{min}$ under a nitrogen atmosphere. The parameters of interest (i.e., melting temperature $\left(T_{m}\right)$, glass transition temperature $\left(T_{g}\right)$, cold crystallization temperature $\left(T_{c}\right)$, melting $\left(\Delta H_{m}\right)$ and cold crystallization enthalpy $\left(\Delta H_{c}\right)$ were measured at the second heating scan. The exception is for the $T_{m}$ of the LDPE, only visible on the first heating scan. The equation of the percentage of crystallinity is as follows (Benali et al., 2015):

$\frac{\chi_{c}(\%)=\left[\Delta H_{m(t)}-\Delta H_{c(t)}\right.}{\left.\Delta H_{m}^{0}\right] \times 100}$

Where $\Delta H_{m(t)}$ et $\Delta H_{c(t)}$ are the melting and the cold crystallization enthalpy at the same time $t$ (after or before the immersion in marine environment) and $\Delta H_{m}^{0}$ is the melting enthalpy of the $100 \%$ crystalline polymer. The $\Delta H_{m}^{0}$ value for PLA is $93.0 \mathrm{Jg}^{-1}$ (Benali et al., 2015), for PBAT it is $114.0 \mathrm{Jg}^{-1}$ (Bastarrachea et al., 2010) and for LDPE it is $293.0 \mathrm{Jg}^{-1}$ (Morawiec et al., 2005).

\subsubsection{Size exclusion chromatography (SEC)}

Polymer solutions were prepared at $2 \mathrm{mg}$ polymer/ $\mathrm{ml}$ of $\mathrm{CHCl}_{3}$. The SEC procedure used is the same as that described previously (Paul et al., 2003). For the analysis of the molecular weight parameters such as the number average molecular weight $\left(\mathrm{M}_{n}\right)$ and the dispersity $\left(\mathrm{D}_{M}\right)$, an Agilent liquid chromatograph was used. $100 \mu \mathrm{l}$ of the samples were injected with an Agilent auto-sampler at a flowrate of $1 \mathrm{ml} / \mathrm{min}$. The calibration was performed with PS standard for separation of $\mathrm{M}_{\mathrm{w}}$ (PS) ranging from 200 to $4 \times 10^{5} \mathrm{~g} / \mathrm{mol}$.

\subsubsection{FTIR spectroscopy}

The spectra of the surface films were obtained using Fourier transform infrared spectroscopy (FTIR) using the attenuated total reflectance

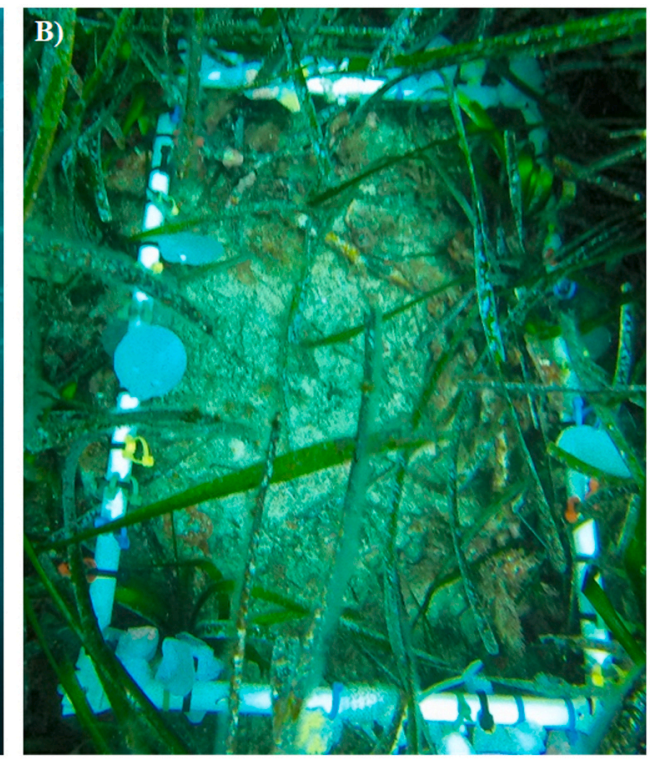

Fig. 1. Experimental design in the Mediterranean Sea: (A) framework in the water column at $4.5 \mathrm{~m}$ of depth and (B) framework on the sediment at a depth of $8 \mathrm{~m}$. 
(ATR) technique (Bruker, Tensor 27) with OPUS 6.5 software. The spectra were acquired over the wavelength range of $4000-600 \mathrm{~cm}^{-1}$ with 64 spectral scans (Mahoney et al., 2013).

\subsection{Bacterial community characterization}

Plastic films were rinsed using sterile salt water to remove microbes that were not well attached to the biofilm. Biofilm was detached from the plastics film using a sterile inoculation loop and the biomass was used for the DNA extraction and for the enrichment cultures if biomass was sufficient.

\subsubsection{Enrichment culture}

Bacterial communities from compostable plastics were cultured in glass tubes with $5 \mathrm{ml}$ of low carbon source marine medium $\left(30^{\circ} \mathrm{C}\right.$, $140 \mathrm{rpm}$ ), as described previously (Delacuvellerie et al., 2019; Yoshida et al., 2016), and with $2 \mathrm{~cm}^{2}$ of new clean plastic film identical to the one used in-situ (section 1.1.). For example, replicates of FP-PBAT were cultured individually in tubes (a total of 4 tubes for FP-PBAT) with a new PBAT film. The composition of the medium used was as follow: $0.05 \%$ yeast extract, $0.2 \%$ ammonium sulfate, $3.5 \%$ salts (W/V, Sigma Sea Salt) and $1 \%$ trace elements $\left(0.1 \% \mathrm{MgSO}_{4} .7 \mathrm{H}_{2} \mathrm{O}, 0.1 \% \mathrm{FeSO}_{4} .7 \mathrm{H}_{2} \mathrm{O}, 0.01 \%\right.$ $\mathrm{ZnSO} 4.7 \mathrm{H}_{2} \mathrm{O}, 0.01 \% \mathrm{CuSO}_{4} .5 \mathrm{H}_{2} \mathrm{O}$ and $0.01 \% \mathrm{MnSO}_{4} .5 \mathrm{H}_{2} \mathrm{O}$ ) in $20 \mathrm{mM}$ (N-morpholino) propanesulfonic acid (MOPS) $\mathrm{pH} 8$; adapted from Yoshida et al. (2016)). These plastics were sterilised in 70\% ethanol and dried in laminar flow. After 80 days of culture, bacterial communities from developed biofilm were analysed by $16 \mathrm{~S}$ rRNA amplicon sequencing. To obtain enough DNA extracts, the DNA extraction were directly performed on the plastic film. Consequently, the monitoring of the plastic degradation by the chemical analysis were irrelevant since these plastics were heated for the DNA extraction.

\subsubsection{DNA extraction and PCR and 16S rRNA amplicon sequencing}

The DNA of biofilm from plastic films was extracted with the Power soil $₫$ DNA kit (Power soil $®$ DNA kit, QIAGEN) following the manufacturer's instructions. A sequence of 460 bp of the hypervariable V3-V4 region of the 16S rRNA of Bacteria and Archaea was amplified using the following primers: 806R (5'-GGACTACNNGGGTATCTAAT-3') and 341F (5'-CCTAYGGGRBGCASCAG-3') (Nunes et al., 2016). Overhang adapter sequences are added to the primer pair sequences to allow the compatibility with Illumina index and sequencing adapters. The sequencing of 2x300 bp paired-end high-throughput were performed with the Illumina ${ }^{\circledR}$ MiSeq ${ }^{\circledR}$ platform (Illumina, San Diego, CA, USA) according to the manufacturer's instructions using the high-throughput sequencing by the GIGA, Liège, Belgium. The version 4.0.3 of the MG-RAST pipeline was used to create the contingency table at the genus level, using Greengenes database, at a sequence identify level of $97 \%$ on the paired-end mating sequences (Keegan et al., 2016). Only mate pairs (forward and reverse) were used for the following analysis. The following options were chosen for the submission on MG-RAST: minimum quality of $25 \mathrm{bp}$ and maximum low quality basepairs of 6 . Using a bit-masked k-difference matching algorithm, adapter sequences were removed. Depending of the options chosen, the sequences were filtered based on number of ambiguous bases, on length and quality values. Finally, PCR artifacts and host DNA contamination were removed (https ://www.mg-rast.org/). 16S rRNA amplicon sequences were deposited at the SRA (Sequence Read Archive) in NCBI under the accession number PRJNA689769 (http://www.ncbi.nlm.nih.gov/bioproject/6897699).

\subsubsection{Analysis of the diversity index}

The PAST software was used to verify the sequencing quality using rarefaction curves. (Fig. S3) (Hammer et al., 2001). The alpha-diversity indices (the richness and the equitability) were calculated on the rarefied data (9871 reads counts for in-situ analyses and 16,779 reads counts for the enrichment culture, Limma RGui package). The statistical significance of the diversity indexes was performed by ANOVA followed by
Tukey's post-hoc analysis (p-value $<0.05$ ). The beta-diversity was studied using multivariate analysis with the PERMANOVA test (vegan RGui package; Wang et al., 2012). This analysis tested the factor significance (plastic type, plastic chemical composition, sample place) using the Bray-curtis dissimilarity with 10, 000 permutations (Table S1). Non-metric multidimensional scaling (nMDS) profile of the pairwise community dissimilarity (Bray-Curtis) indices of the $16 \mathrm{~S}$ sequencing data was realized using the PAST software (Hammer et al., 2001). Identification and validation of response groups (RGs).

\subsubsection{Identification and validation of response groups (RGs)}

A heatmap was performed with 30 OTUs significantly affected by the sample position (sediment $v s$ water column). These OTUs were identified using a nbGLM (negative binomial distribution and Generalized Linear Model), a deviance analysis carried out by the utilization of the mvabund Rgui package (Dixon, 2003) revised by 1000 resampling iterations of the residual variance $(\mathrm{p}<0.05)$. Two RGs were defined with a cluster dendrogram using the Euclidean distance and an average clustering (vegan RGui package). These two response groups were validated against a null model by Monte-Carlo simulation (Fig. S4) containing all the OTUs to reinforce the power of randomization (Cyriaque et al., 2020).

\section{Results \& discussion}

\subsection{Biofilm formation}

Compostable (semi-crystalline PLA, amorphous PLA and PBAT) and non-compostable plastics (PET, LDPE, PS and PVC) were submerged during 82 days into the sea (Fig. 1): (1) on the sediment ( $8 \mathrm{~m}$ depth) and (2) into the water column ( $4.5 \mathrm{~m}$ depth). We used seven different polymers which have different structure: (i) commodity plastics (PET, LDPE, PVC and PS) whose polymer chain hardly degrades (ii) and compostable plastics displaying a hydrolytically unstable matrix. These plastics were immerged on the sediment and in the water column to vary the aging conditions of these plastics. Unfortunately, several plastic films, mainly plastic in the water column, were lost during the immersion time due to the weather conditions (currents and swells) (Table S2). Concerning remaining plastics, after the immersion, macroscopic observations of the biofilm on the polymer revealed differences depending on the polymer position (sediment (SP) $v s$ floating plastics (FP) in the water column) (Fig. 2), showing that the position conditions (e.g., light or pressure) impacts the biofilm formation. The biofilm colour ranged from green for the FP samples to brown and pink for SP polymers. However, no difference was observed with the plastic chemical composition (LDPE, PBAT, PLA, etc.). For both plastic types (compostable or non-compostable plastics), the biomass varied depending on the position on the frame (Table S2). This observation confirms our previous results studying bacterial communities of collected polluting plastics in the Mediterranean Sea (Delacuvellerie et al., 2019) and can be explained by several parameters such as the different exposition of the ultraviolet (UV) radiations, of the water stream, water temperature, etc.

\subsection{Physicochemical properties of the plastic films after immersion in marine environment}

\subsubsection{PS, $P V C \& P E T$}

Regarding weight loss (Fig. 3), ATR-FTIR spectra and SEC (Table 3) and DSC (Table 4) parameters, no parameters significantly change for the SP and FP samples after the 82 days of immersion, excepted for the PVC for which a slight weight gain is observed. This gain is due to the sorption of water. The general visible aspect of the polymer is a critical indication about their hydrolysis. No difference was observed except for the FP-PVC samples whose films were brownish (Fig. S5). The dehydrochlorination process of PVC which leads to the formation of polyene sequences or long conjugated double bonds can cause this colour change 
Table 3

Size exclusion chromatography parameters of polymers at the initial time $\left(\mathrm{t}_{\mathrm{i}}\right.$; before the immersion), and after the 82 days of immersion into the Mediterranean Sea on the sediment (Sediment) or in the water column (Water column); NA: samples lost during the immersion time. The shape of SEC trace is monomodal for each sample.

\begin{tabular}{llll}
\hline Polymer & Sample name & $\overline{M_{n}}(\mathrm{~g} / \mathrm{mol})^{\mathrm{a}}$ & $\oplus_{\mathrm{M}}$ \\
\hline \multirow{2}{*}{ PLA (4032D) } & $\mathrm{t}_{\mathrm{i}}$ & 130,000 & 1.8 \\
& Sediment & 100,000 & 1.8 \\
& Water column & 100,000 & 1.9 \\
PLA (4060D) & $\mathrm{t}_{\mathrm{i}}$ & 140,000 & 1.8 \\
& Sediment & 120,000 & 1.8 \\
& Water column & $\mathrm{NA}$ & $\mathrm{NA}$ \\
PBAT & $\mathrm{t}_{\mathrm{i}}$ & 52,000 & 2.9 \\
& Sediment & 51,000 & 2.9 \\
& Water column & 44,000 & 3.8 \\
PS & $\mathrm{t}_{\mathrm{i}}$ & 140,000 & 2.5 \\
& Sediment & 150,000 & 2.5 \\
& Water column & 140,000 & 2.7 \\
\hline
\end{tabular}

$$
{ }^{\text {a }} \text { PS standard }
$$

(Sombatsompop and Sungsanit, 2004). In the water column, near the surface, the polymer is more exposed to UV radiations, explaining this difference between the water column and the deeper sediment. PVC is the most sensitive polymer toward UV radiations (Gewert et al., 2015).

In conclusion, FP-PVC is thought to undergone a process of dehydrochlorination due to the UV radiation effects in the water column. However, these three non-compostable plastics (PVC, PS and PET) on sediment and in the water column were not degraded after immersion in natural marine environment.

\subsection{2. $L D P E$}

Interestingly, the physicochemical parameters of the LDPE on the sediment and in the water column after the immersion were different. Concerning the SP-samples, no chemical parameters displayed changes between the initial time and the end of the immersion (Fig. 3; Table 3 and 4). However, concerning the FP-films, a small increase of the $T_{g}$ was observed $\left(46-48{ }^{\circ} \mathrm{C}\right)$ as well as a rise of the crystallinity $(40-42 \%)$. These

\section{Table 4}

Differential scanning calorimetry parameters from the second heating for each polymer at the initial time ( $\mathrm{t}_{\mathrm{i}}$ : before the immersion), and after the 82 days immersion in the Mediterranean Sea on the sediment (Sediment) or in the water column (Water column); * only one replicate; NA: samples lost during the immersion time; ${ }^{a}$ values from the first heating scan.

\begin{tabular}{lllll}
\hline Polymer & Sample name & $\mathrm{T}_{\mathrm{g}}\left({ }^{\circ} \mathrm{C}\right)$ & $\mathrm{T}_{\mathrm{m}}\left({ }^{\circ} \mathrm{C}\right)$ & $\chi_{\mathrm{c}}(\%)^{\mathrm{a}}$ \\
\hline \multirow{2}{*}{ PLA (4032D) } & $\mathrm{t}_{\mathrm{i}}$ & 62 & 166 & 4 \\
& Sediment & 61 & 166 & 4 \\
& Water column & $61^{*}$ & $166^{*}$ & $4^{*}$ \\
PLA (4060D) & $\mathrm{t}_{\mathrm{i}}$ & 58 & $/$ & Amorphous \\
& Sediment & 58 & $/$ & Amorphous \\
& Water column & $\mathrm{NA}$ & $\mathrm{NA}$ & $\mathrm{NA}$ \\
PBAT & $\mathrm{t}_{\mathrm{i}}$ & -29 & 121 & 14 \\
& Sediment & -29 & 120 & 14 \\
& Water column & -29 & 121 & 14 \\
PS & $\mathrm{t}_{\mathrm{i}}$ & 106 & $/$ & Amorphous \\
& Sediment & 105 & $/$ & Amorphous \\
& Water column & 105 & $/$ & Amorphous \\
PET & $\mathrm{t}_{\mathrm{i}}$ & 94 & $/$ & Amorphous \\
& Sediment & 94 & $/$ & Amorphous \\
& Water column & 94 & $/$ & Amorphous \\
PVC & $\mathrm{t}_{\mathrm{i}}$ & 76 & $/$ & Amorphous \\
& Sediment & 75 & $/$ & Amorphous \\
& Water column & 75 & $/$ & Amorphous \\
LDPE & $\mathrm{t}_{\mathrm{i}}$ & 46 & 109 & 40 \\
& Sediment & 46 & 109 & 41 \\
& Water column & 48 & 109 & 42 \\
\hline
\end{tabular}

$$
{ }^{\mathrm{a}} \chi_{c} \quad(\%)=\frac{\left[\Delta H_{m(t)}-\Delta H_{c(t)}\right.}{\left.\Delta H_{m}^{0}\right] \times} 100
$$

two parameters indicated that the amorphous zone of the LDPE could be slightly degraded increasing the crystallization percentage. Moreover, on the ATR-FTIR spectra (Fig. S7), a new peak was visible at $1715 \mathrm{~cm}^{-1}$, corresponding to a ketone carbonyl function. The photooxidation of the polyethylene happens as followed: UV radiation effects lead to the formation of radicals which react with dissolved oxygen in the marine environment and form a ketone carbonyl bond (Albertsson et al., 1987). This degradation was only observed in FP-LDPE, most likely because in the water column UV radiation intensity is higher than on the deeper sediment (Sudhakar et al., 2007). This photooxidation forms a new oxidative functional group and changes the plastic surface properties. Unfortunately, several plastic films, mainly plastic in the water column, were lost during the immersion time due to the weather conditions (currents and swells) (Table S2) that might have facilitate the biodegradation processes (Gilan et al., 2004; Cornell et al., 1984). In conclusion, a degradation by photooxisation was observed on LDPE samples in the water column but this degradation is relatively low, with a weight loss of $0.04 \%$ (Fig. 3).

\subsubsection{PLA \& PBAT}

Concerning the degradation of these three compostable plastics, no difference was observed in the DSC parameters $\left(M_{n}\right.$ and $\left.\boxplus_{M}\right)$ and the ATR-FTIR spectra between the initial time and the end of the immersion both on the sediment and in the water column. However, the cold crystallization enthalpy and the melting enthalpy of FP- and SP- PLA 4032D were higher after the immersion of the polymer (Fig. S6). Regarding the SEC parameters of the PLA 4032D, the $M_{n}(130,000$ to $100,000 \mathrm{~g} / \mathrm{mol}$ ) decreased for both the SP and FP samples. The shape of the SEC trace remained monomodal. However, there was no weight loss and no new peak on the ATR-FTIR spectra indicating that the PLA hydrolysis starts with a homogeneous shortening of the chain, with a low efficiency. The UV radiations did not impact the PLA degradation, but the chemical analyses of the FP-PLA were performed only on one replicate.

Concerning the PLA amorphous (4060D), no samples were collected in the water column. When being degraded, these polymers may become fragile and prone to break and leave from the structure. The second hypothesis is that these plastics are more brittle and did not tolerate the storm. For the SP-PLA 4060D, the $\mathrm{M}_{\mathrm{n}}$ was the only parameter that varied with a decrease from $140,000 \mathrm{~g} / \mathrm{mol}$ at the initial time to $120,000 \mathrm{~g} / \mathrm{mol}$ after the immersion, suggesting that hydrolysis has begun.

We hypothesize that after 82 days of immersion in natural marine environment of the Mediterranean Sea (water temperature around $20{ }^{\circ} \mathrm{C}$ ), there was no drastic degradation of amorphous and semicrystallin PLA. These results are in agreement with the literature. Indeed, the PLA is known for its biodegradability in industrial composting but not in marine environments at $30^{\circ} \mathrm{C}$ (in a bioreactor) (Naranci et al., 2018). However, signs of degradation were showed for the PLA incubated in buffer at $37^{\circ} \mathrm{C}$ after 1.5 month, i.e. $\mathrm{M}_{\mathrm{w}}, \mathrm{T}_{\mathrm{g}}$ and $\mathrm{T}_{\mathrm{c}}$ significantly decreased while the $\chi_{c}$ increased (Benali et al., 2015). Moreover, it was reported that the PLA degradation vary according to the water temperature: the lower is the temperature, the slower is the biodegradation process (Volova et al., 2007). However, the impact of the sample position (sediment $v s$ water column) cannot be confirmed as only one replicate of PLA 4032D and no PLA 4060D was sampled in the water column. In a recent study, the PLA degradation into cylinders simulating different marine compartment reached a weight loss of $1 \%$ in the water column and around $20 \%$ when immerged in the sediment (Beltran-Sanahuja et al., 2020). In the present study, the experimental design mimics plastics moving freely on the sediment hance a decreasing access to the organic matter.

Finally, the FP and SP-PBAT have lost $1.1 \pm 0.1 \%$ and $1.5 \pm 0.3 \%$, respectively (Fig. 3). Concerning the SEC parameters of FP-PBAT, the $\mathrm{M}_{n}$ decreased $\left(52000 \mathrm{~g} / \mathrm{mol}\right.$ to $44,000 \mathrm{~g} / \mathrm{mol}$ ) and the $\bigoplus_{M}$ increased (from 2.9 to 3.8), suggesting it started hydrolysing. However, there was no difference between the PBAT at the initial time and after the immersion 
on the sediment. Concerning the PBAT, only a very few studies have been performed on its biodegradability in marine water in laboratory conditions at room temperature. PBAT lost less than $2.5 \%$ of its weight over 56 weeks of immersion in tanks with natural sea water (Wang et al., 2019). All the SEC parameters for the FP-PBAT were also different further suggesting that the position in the water column led to a better degradation of PBAT plastics due to the higher temperature, greater mixing water, UV radiation, etc.

\subsection{Bacterial community composition of the plastisphere}

Physicochemical analysis highlighted that the marine environment had differential impacts on the different chemical composition of plastic due to their differences in structure; i.e., oxidation for FP-LDPE, dichlorination for FP-PVC, etc. To better understand the impact of bacterial degradation on compostable and non-compostable plastics, and to study the bacterial community assembly on these two types of polymers in marine environment, the bacterial community composition was studied by the $16 \mathrm{~S}$ rRNA amplicon sequencing. Despite the different abiotic degradation steps of plastics, will some of these polymers be used as a carbon source by microorganisms in order to degrade them?

The alpha-diversity of the microbial communities of plastics immerged during 82 days on sediment (SP) and in the water column (FP) were measured using 16S rRNA amplicon sequencing (Fig. 4). No significant difference was revealed between the plastic chemical composition (LDPE, PS, PVC, PET, PLA 4032D, PLA 4060D and PBAT) upon the same position (FP or SP). Unsurprisingly the richness index on SP is significantly higher than on FP-samples (p_value: $6.984 \mathrm{e}^{-4}$ ). Indeed, SPplastics were in contact with sediment that possess a higher concentration of microorganisms than those in the water column. nMDS analysis highlighted the distinctness of the bacterial communities on plastics depending on their position (FP vs SP) (Fig. S8). No discrimination between bacterial communities developed on compostable and noncompostable plastics or between the different plastic chemical compositions were highlighted.

The plastisphere community was mostly represented by Proteobacteria, especially Gamma- and Alphaproteobacteria. Bacteroidetes represents the second dominant group (Fig. S9). The first two groups are known in the literature to be the primary colonizers in a marine plastic biofilm, while Bacteroidetes are usually secondary colonizers (De Tender et al., 2015). In correlation with the nMDS results, there was no difference depending on the plastic chemical composition, but, a difference in the bacterial composition can be highlighted depending on the plastic position (SP vs FP). Bacteroidetes, Actinobacteria and Firmicutes were

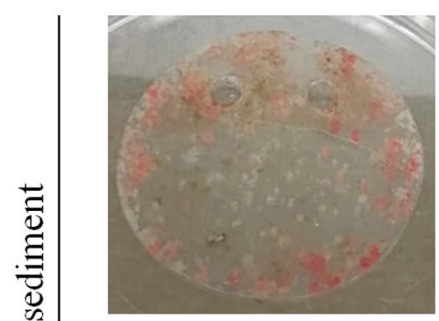

LDPE

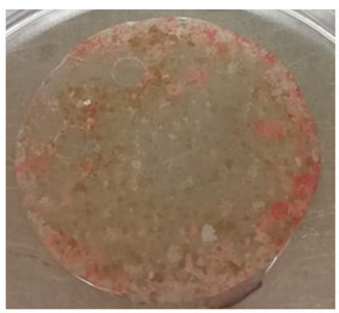

PS

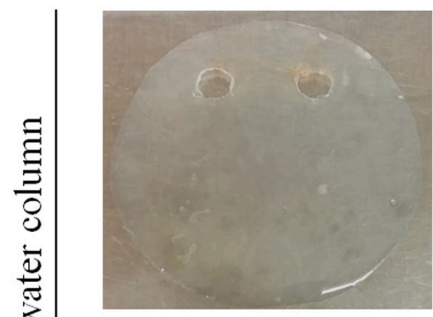

LDPE

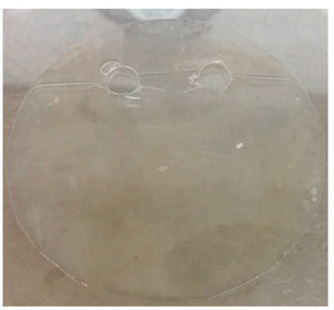

PS

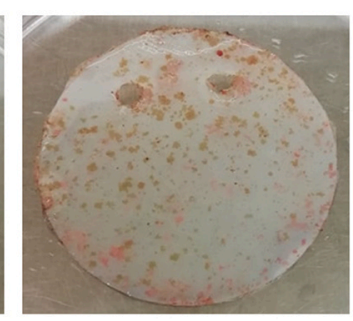

PBAT

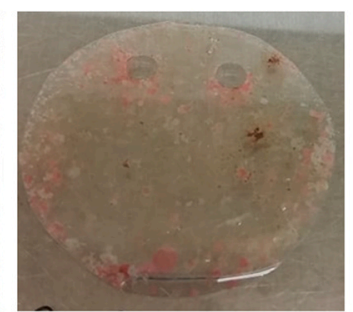

PVC

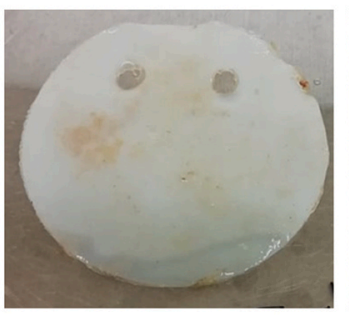

PBAT

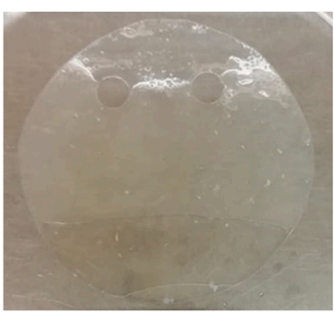

PVC

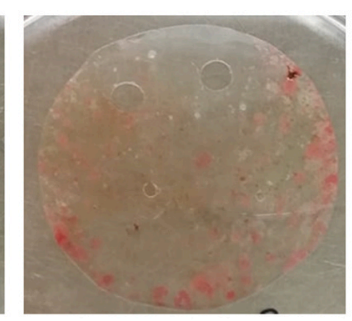

PET

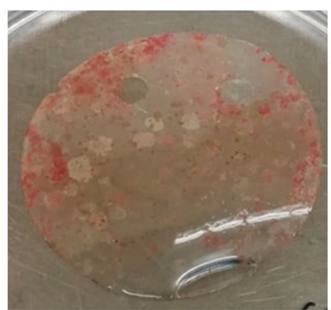

PLA (4060D)

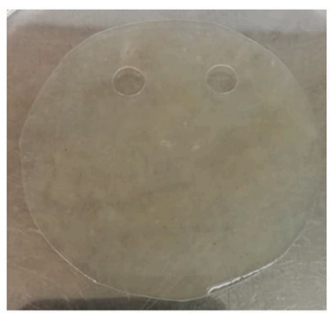

PET

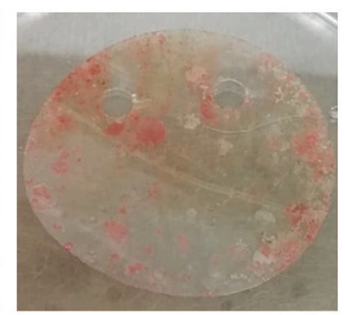

PLA (4032D)

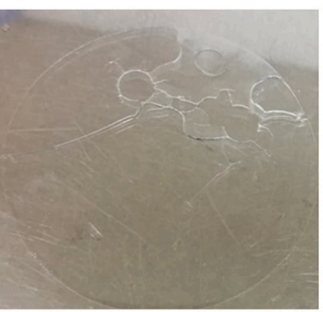

PLA (4032D)

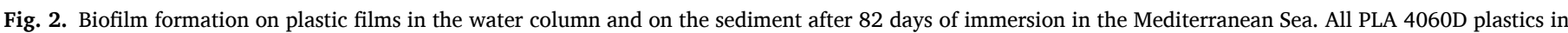

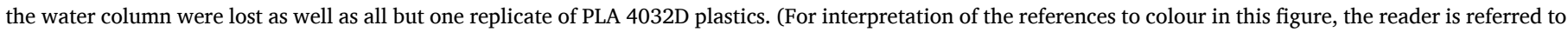
the web version of this article.) 

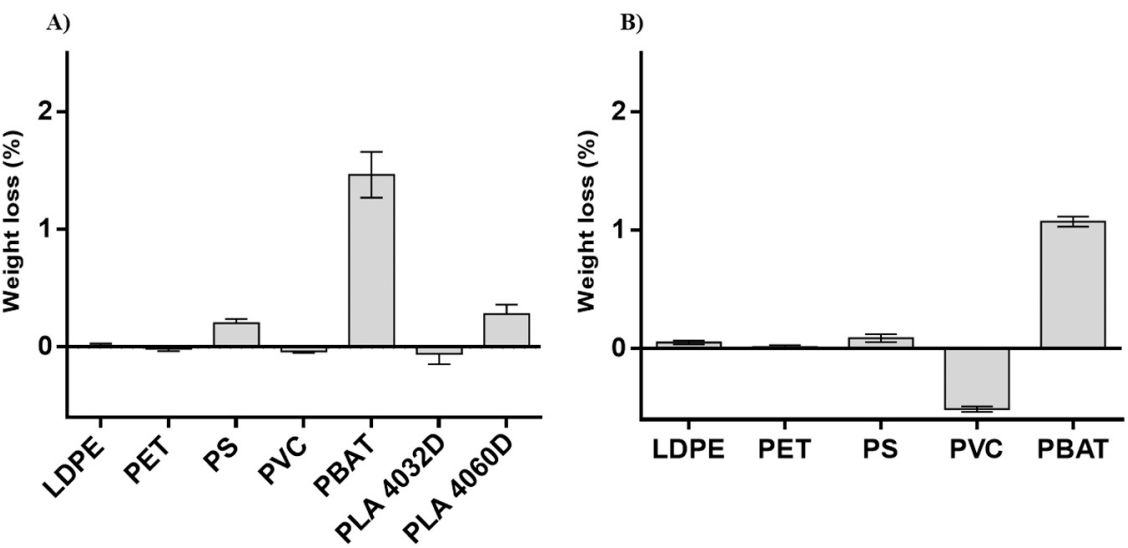

Fig. 3. Plastic weight loss after immersion into the Mediterranean Sea; (A) on the sediment or (B) in the water column.

more abundant on SP, contrary to FP in which the Alphaproteobacteria were more abundant. Vibrionaceae was the most abundant family on all the samples (Fig. 5 and Table S3). Clostridiaceae, Actinomycetaceae, Fucacceae, Acinetosporaceae and Fragilariaceae were more abundant on SP, while Pseudoalteromonadaceae and Shewanellaceae were more abundant on FP.

Interestingly, 30 OTUs were significantly affected (nbGLM, $p$-value $<$ 0.05) by the sample position (FP vs SP) (Fig. 6). SP-specific OTUs were highly represented. These results are supportied by the alpha-diversity as SP-samples displayed a higher richness. Shewanella, Arcobacter and unclassified Alphaproteobacteria were specific to the FP-plastics. No specific OTUs was affected depending on the polymer type and chemical composition (compostable/non-compostable or LDPE /PET /PVC /PS/ PLA4032D/ PLA4060D/ PBAT).
PERMANOVA, nMDS analysis and the heatmap (Table S1, Fig. 6 and Fig. S8) show a distinctness between bacterial composition from SP and FP samples, as previously observed (Delacuvellerie et al., 2019). This difference comes from several parameters acting upon the sample position (i.e., more accessible light and higher temperature, etc in FP-sample favours the Cyanobacteria growth). Moreover, this difference can be also explained by the fact that the FP-plastics were more exposed to the UV radiations than SP-plastic. UV radiations can have direct and indirect effects on bacteria such as decreasing their growth or activity (Elasri and Miller, 1999; Davidson and Belbin, 2002). Microbial communities are impaired by solar radiations due to direct deleterious effects of radiation on macromolecules such as DNA and proteins. Moreover, photo-oxidation can cause an abiotic degradation of the plastic (e.g., LDPE in the water column) and change its surface properties
A)

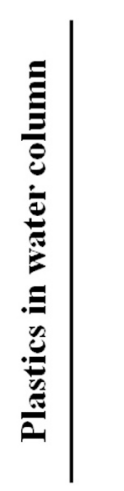

|

C)
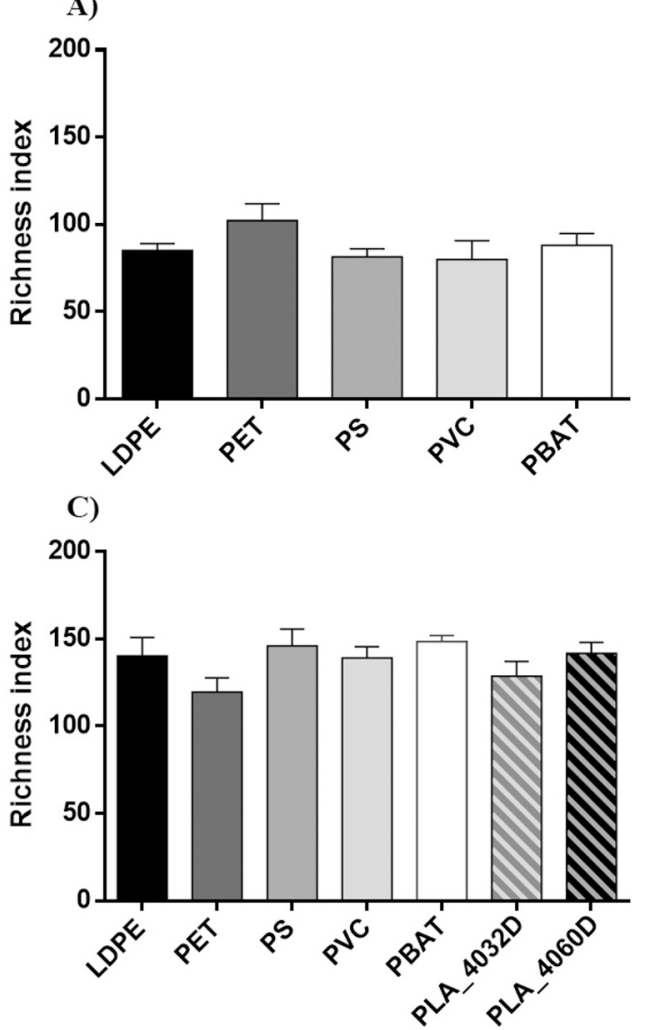

B)

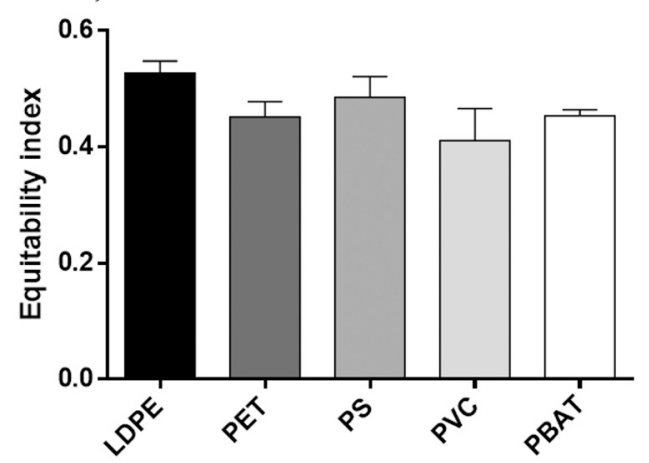

D)

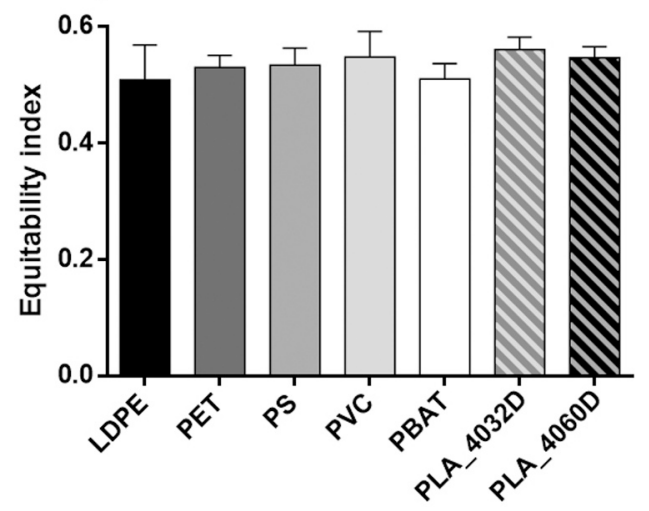

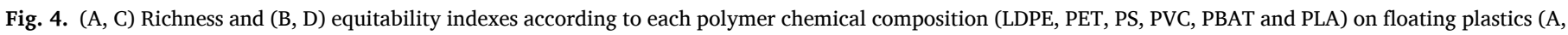

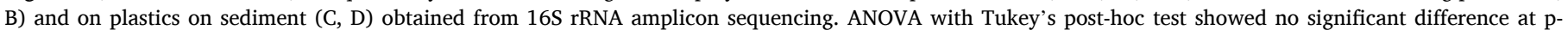
value $<0.05$. 


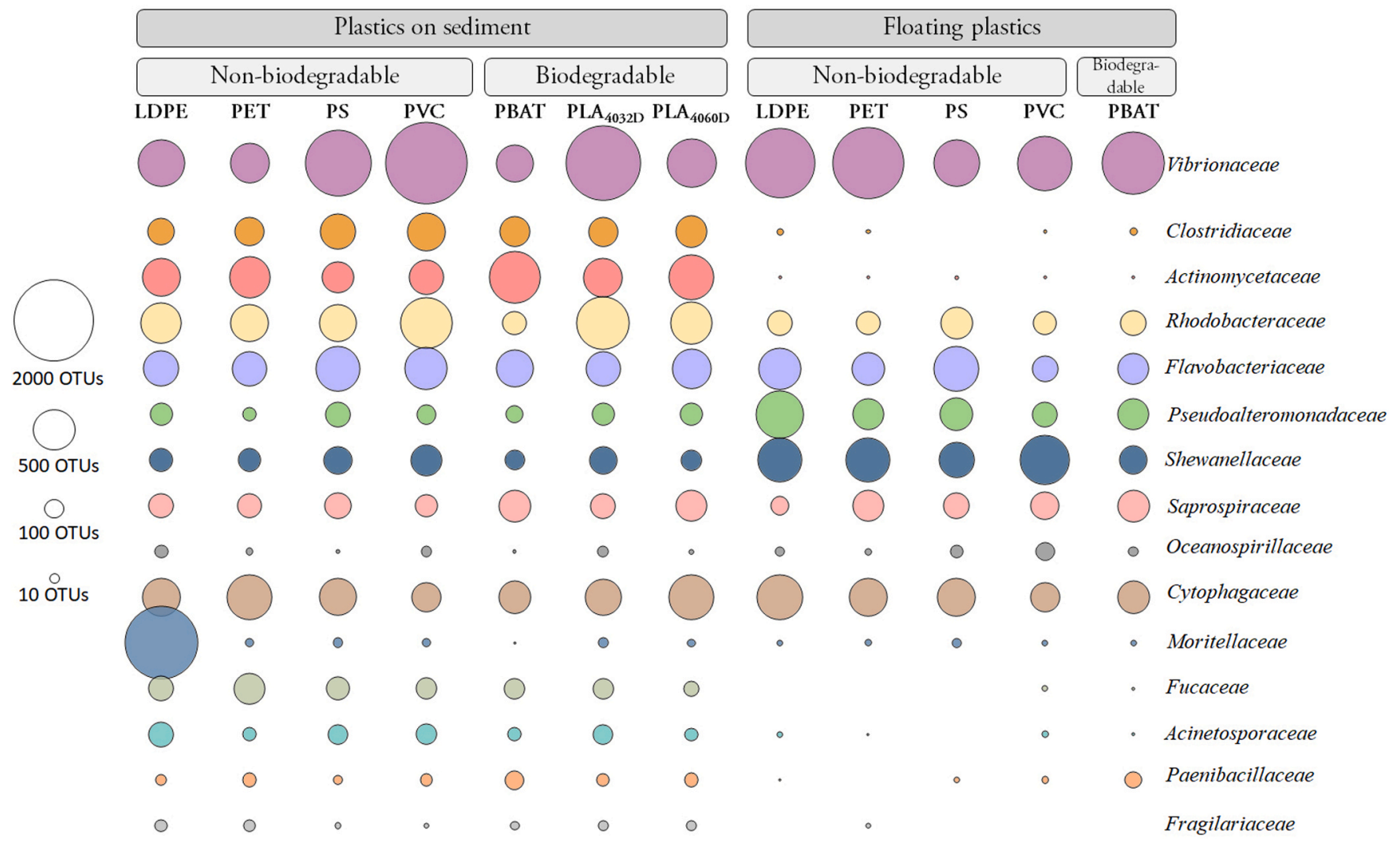

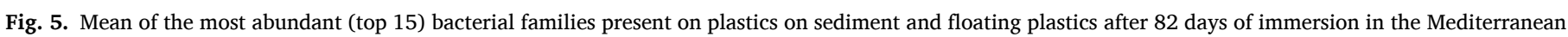
Sea. The average \pm SEM of these families are provided in table S6.

such as its topography, chemistry and roughness (Rummel et al., 2017).

No significant difference was observed between the different polymer chemical composition (PET, LDPE, PVC, PS, PBAT, PLA4032D and PLA 4060D) or on the plastic type (compostable/non-compostable). Several studies showed that at the initial colonization of the plastics (1 week), the polymer chemical composition and the surface characteristics influence the bacterial community composition. But later in time, the microbial composition is more influenced by internal biofilm processes, which leads to a decrease in the difference of the bacterial composition between the different polymers. As a consequence, only a small fraction of microorganisms are polymer type-specific (e.g., Cryomorphaceae or Alcanivoraceae family are discriminant on the PET (Oberbeckmann et al., 2016), and a bacterial core is shared among all the polymers (Kirstein et al., 2018). In our study, no genus is specific of a polymer. As it was showed in other studies, the plastic serves as an attachment surface for the bacteria in biofilms with no specific selection for their degradation capabilities (Pinto et al., 2019; Oberbeckmann et al., 2016; Cheng et al., 2020). Concerning the PLA, previous study showed that no evidence of bacterial degradation was observed in seawater after 10 weeks (Karamanlioglu et al., 2017). This result corroborates the degradation chemical analysis of the polymers. Indeed, bacterial communities developed on the compostable or non- compostable plastics were not specific for the polymer type and chemical composition but mainly used the plastic as a growing physical support without using the polymer as a carbon source. So, despite the fact that the seven plastics have distinct structure and have undergone abiotic degradation, natural bacterial community from the water column or from the sediment used other carbon sources more accessible in the marine environment and not the plastics.

On both SP and FP samples, Vibrionaceae is the most represented family (Fig. 5). This family is mainly composed by the Vibrio genus and contains numerous pathogenic species. Studies showed that bacteria belonging to Vibrio are often found in higher concentration on plastics than in the natural environments (lower than 1\%) (Thompson and Polz, 2006; Kirstein et al., 2016). Moreover, a heatmap (Fig. 6) highlighted 3 well represented OTUs on the FP-plastics: Shewanella, Arcobacter and unclassified_Alphaproteobacteria. Shewanella and Arcobacter genera also contain pathogen species for fish and human (Janda, 2014; Koziñska and Pekala, 2004; Maugeri et al., 2004) corroborating the hypothesis that plastic serve as a vector for fish, bird or human pathogens (Zettler et al., 2013). Even if they are not involved to the polymer degradation, pathogenic bacteria may hitchhike on plastics (Debroas et al., 2017). Plastics can serve as rafts for microorganism species and host bacteria that are usually not detected in the marine environment. Therefore, they have a major impact on ecosystems. Invasive or pathogens species might travel to new environments and disturb the entire ecosystem (De Tender et al., 2015).

\subsection{Bacterial selection in enrichment culture}

In an attempt to select potential candidates that can degrade compostable plastics in ideal conditions for biotechnology purpose (PLA_4032D, PLA_4060D and PBAT), and to see the implication of some bacteria in the biodegradation of compostable plastics, the bacterial biofilm developed on SP- and FP-PBAT and SP-PLA were grown, each replicate individually, with plastic film as the main carbon source as previously described (Delacuvellerie et al., 2019). After 80 days of culture, we obtained macroscopically visible biofilms (Fig. S10) and analysed the settled microbial community using 16S rRNA gene amplicon sequencing. The equitability and the richness indices after enrichment were lower than the one observed at the initial time (Fig. 4 \& S11), highlighting a selection process. The bacterial community was mostly represented by Alpha-, Gammaproteobacteria and Bacteroidetes on the three types of polymers (Fig. S12). The weight loss method was used to 


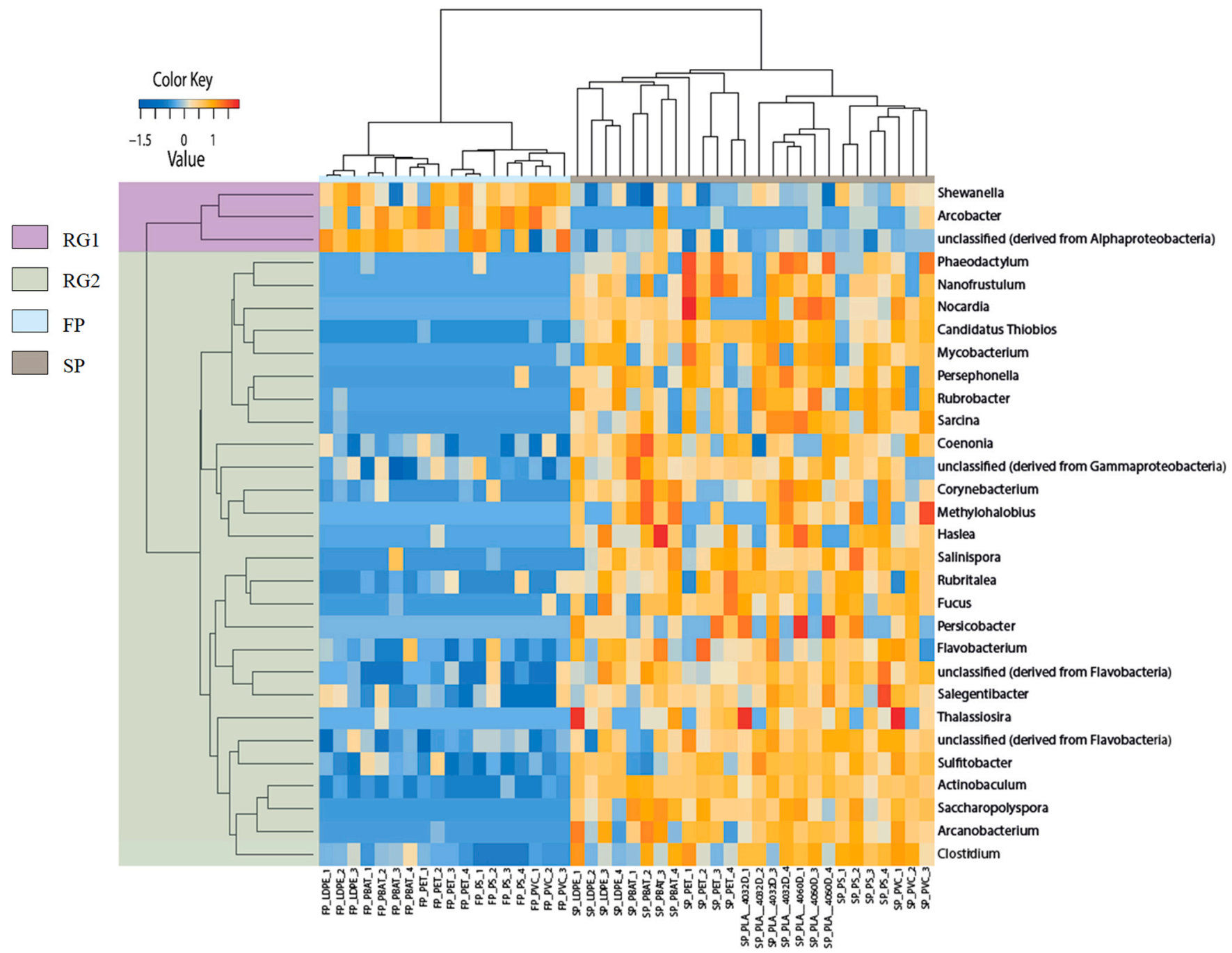

Fig. 6. Heatmap of the 30 genera significantly affected by the sample position: plastics on sediments (SP) and floating plastics (FP). Two response groups (RGs) were defined with hierarchical clustering based on center-scaling abundance.

follow the plastic degradation after the culture (Fig. 7). Interestingly, FP-PBAT lost $12.4 \pm 2.5 \%$ while SP-PBAT, SP-PLA-4032D and SP-PLA-4060D lost less than $2 \%$. To understand this difference, we monitored the bacterial composition difference of the SP-PBAT and FP-PBAT samples by a nbGLM. The genus Marinomonas constituted the only different genus between both communities ( $p_{-}$value: 0.046$)$. This genus was mainly represented on the FP-PBAT. Finally, we followed the percentage of genus containing putative hydrocarbonoclastic bacteria in the bacterial population before and after the enrichment culture

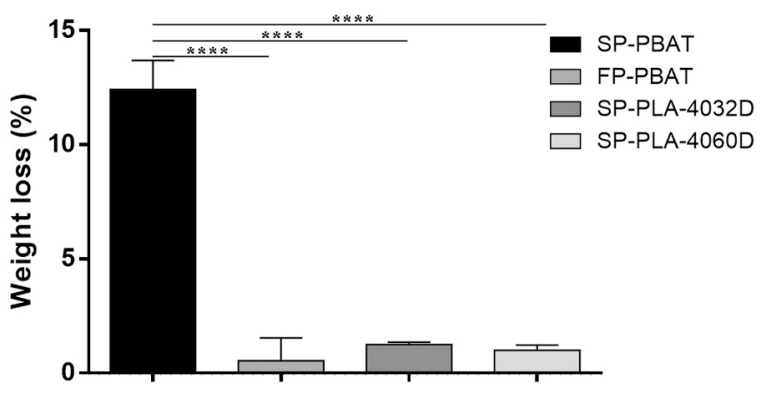

Fig. 7. Plastic weight loss after 80 days of enrichment culture. ANOVA with Tukey's post-hoc test; *, $p<0.05 ; * *, \quad p<0.01 ; * * *, \quad p<0.001$; $* * * *, p<0.0001$.
(Arenibacter, Bacillus, Desulfovibrio, Marinobacter, Phaeobacter, Fig. S13). Most of these genera displayed a larger proportion of the bacterial population on the three polymers after the enrichment (p-value in Table S4).

The selection of this putative hydrocarbonoclastic bacteria genera leads to a decrease in the richness and equitability indexes. The selection of these bacteria can be explained by 2 factors: (i) The plastic-dwelling microorganisms may possess the metabolic pathways to degrade plastic whose chemical structure is close to hydrocarbons that became the only carbon source in their environment (Delacuvellerie et al., 2019; Zettler et al., 2013) and (ii) plastics being hydrophobic means that hydrocarbonoclastic bacteria are able to overcome the poor accessibility of these substrates and thus play a crucial role in the colonization of the hydrocarbon-water interface (Lobelle and Cunliffe, 2011). This biofilm formation has been shown to facilitate interphase access (plastic-water interface) and promote the bacterial growth. The first hypothesis would explain why we observed a weight loss on the FP-PBAT. In order to understand why there is no degradation of the SP-PBAT, the bacterial compositions were compared. One genus, Marinomonas, is significantly more represented on the FP-PBAT compared to SP-PBAT after enrichment (Fig. S13). Several species of Marinomonas can use the adipic acid as carbon source (Zhang and Margesin, 2015). This compound is issued from the hydrolyzation of the PBAT (Muthuraj et al., 2015). Thus, this bacterium might have enzymes able to degrade the PBAT into adipic 
acid and use it as carbon source. However, before the enrichment culture, this genus is also present on FP-plastic where no weight loss was observed. The latter observation could be explained by the second hypothesis. This bacterium used the plastic surface as a hydrophobic substrate and it is not the favorable conditions in order to degrade it due to the presence of other carbon source more accessible in the natural marine environment.

\section{Conclusion}

We evaluated the biodegradability of compostable and noncompostable plastics in natural marine environment. After 82 days in natural marine environment, the sample position (sediment $v s$ water column) was found to influence not only the abiotic degradation of the plastic but also the bacterial community composition developed on these polymers. However, the observed degradation signs were very low and there was no significant degradation of the compostable and noncompostable polymers. As reminder, the impact of the sample position on the PLA plastic cannot be confirmed due to the loss of PLA-FP during the immersion. Moreover, microbial composition did not depend on the plastic type (compostable vs non-compostable) or plastic chemical composition (LDPE, PS, PET, PVC, PLA 4032D, PLA 4060D and PBAT). In natural marine environments, bacterial communities developed on the compostable or non-compostable plastics seem to be unspecific for the polymer degradation and used the plastic mainly as a physical growing support. Despite the fact that the seven plastics have distinct structures and have undergone abiotic degradation, natural bacterial community on the plastics from the water column or from the sediment were not significantly selected due to the large amount of carbon availability in the marine environment. Consequently, bacteria did not use the polymer as a carbon source and did not help to the plastic degradation. However, in enrichment culture, the presence of genera such as Marinomonas seems to improve the PBAT degradation with a weight loss of $12 \%$, indicating that a preselection of bacteria in an ideal condition aids the biodegradation. A better understanding of the bacterial biofilm composition developed on plastic is essential to develop realistic standard tests to evaluate the biodegradability of these polymers. Current standards and norms used are insufficient to predict biodegradability in aquatic environment. In contrast, a better understanding of this system would allow for the eco-design of new polymers having optimizing properties and displaying matrix structure with a strong selective advantage over other carbon sources, thus being more accessible and having improved biodegradation in marine environments.

\section{CRediT authorship contribution statement}

Alice Delacuvellerie: Methodology, Formal analysis, Investigation, Writing - original draft preparation, Conceptualization. Samira Benali: Writing - review \& editing, Methodology. Valentine Cyriaque: Writing - review \& editing, Formal analysis. Sébastien Moins: Methodology. Jean-Marie Raquez: Writing - review \& editing, Resources. Sylvie Gobert: Methodology, Writing - review \& editing, Resources. Ruddy Wattiez: Supervision, Resources, Writing - review \& editing, Conceptualization, Methodology.

\section{Declaration of Competing Interest}

The authors declare that they have no known competing financial interests or personal relationships that could have appeared to influence the work reported in this paper.

\section{Acknowledgments}

We thank STARESO (the Oceanographic and Underwater Research Station) for their welcome and Laurence and Annick for their help for the placement of the plastic samples. This study is funded by the Fund for Scientific Research (F.R.S-FNRS) FC 23347. Samira Benali acknowledge supports by the European Community (FEDER) for general support in the frame of LCFM-BIOMAT. Jean-Marie Raquez is a FRSFNRS Research Associate.

\section{Appendix A. Supporting information}

Supplementary data associated with this article can be found in the online version at doi:10.1016/j.jhazmat.2021.126526.

\section{References}

Accinelli, C., Sacca, M.L., Mencarelli, M., Vicari, A., 2012. Deterioration of bioplasticcarrier bags in the environment and assessment of a new recycling alternative. Chemosphere 89, 136-143.

Albertsson, A.-C., Andersson, S.O., Karlsson, S., 1987. The mechanism of biodegradation of polyethylene. Polym. Degrad. Stab. 18, 73-87.

Bastarrachea, L., Dhawan, S., Sablani, S.S., Mah, J.H., Kang, D.H., Zhang, J., Tang, J., 2010. Biodegradable poly (butylene adipate-co-terephthalate) films incorporated with nisin: characterization and effectiveness against Listeria innocua. J. Food Sci. 75 (4), 215-224.

Beltran-Sanahuja, A., Casado-Coy, N., Simo-Cabrera, L., Sanz-Lazaro, C., 2020. Monitoring polymer degradation under different conditions in the marine environment. Environ. Pollut. 259, 113836.

Benali, S., Aouadi, S., Dechief, A.-L., Murariu, M., Dubois, P., 2015. Key factors for tuning hydrolytic degradation of polylactide / zinc oxide nanocomposites. Nanocomposites 1, 51-60.

Bioplastics market data report, European Bioplastics (2018)

Cheng, J., Jacquin, J., Conan, P., Pujo-Pay, M., Barbe, V., George, M., Fabre, P., Bruzaud, S., Ter Halle, A., Meistertzheim, A.L., Ghiglione, J.F., 2020. Relative influence of plastic debris size and shape, chemical composition and phytoplanktonBacteria interactions in driving seawater plastisphere abundance, diversity and activity. Front. Microbiol. 11, 610231.

Cornell, J.H., Kaplan, A.M., Rogers, M.R., 1984. Biodegradation of photooxidized polyalkylenes. J. Appl. Polym. Sci. 29, 2581-2597.

Cyriaque, V., Géron, A., Billon, G., Nesme, J., Werner, J., Gillan, D.C., 2020. Metalinduced bacterial interactions promote diversity in river-sediment microbiomes. FEMS Microbiol. Ecol. 96 (6), fiaa076.

Davidson, A., Belbin, L., 2002. Exposure of natural Antarctic marine microbial assemblages to ambientUV radia- tion: effects on the marine microbial community. Aquat. Microb. Ecol. 27 (2), 159-17.

De Tender, C., Schlundt, C., Devriese, L.I., Mincer, T.J., Zettler, E.R., Amaral-Zettler, L.A., 2017b. A review of microscopy and comparative molecular-based methods to characterize "Plastisphere" communities. Anal. Methods 9, 2132-2143.

De Tender, C.A., Devriese, L.I., Haegeman, A., Maes, S., Ruttink, T., Dawyndt, P., 2015. Bacterial community profiling of plastic litter in the Belgian part of the North Sea. Environ. Sci. Technol. 49, 9629-9638.

De Tender, C.A., Devriese, L.I., Haegeman, A., Maes, S., vangeyte, J., Cattrijsse, A., Dawyndt, P., Ruttink, T., 2017a. The temporal dynamics of bacterial and fungal colonization on plastic debris in the North Sea. Environ. Sci. Technol. 49, 9629-9638.

Debroas, D., Mone, A., TerHalle, A., 2017. Plastics in the North Atlantic garbage patch: a boat-microbe for hitchhikers and plastic degraders. Sci. Total Environ. 599-600, $1222-1232$.

Delacuvellerie, A., Cyriaque, V., Gobert, S., Benali, S., Wattiez, R., 2019. The plastisphere in marine ecosystem hosts potential specific microbial degraders including Alcanivorax borkumensis as a key player for the low-density polyethylene degradation. J. Hazard. Mater. 380, 120899.

Dixon, P., 2003. VEGAN, a package of R functions for community ecology. J. Veg. Sci. 14, 927-930.

Dussud, C., Hudec, C., George, M., Fabre, P., Higgs, P., Bruzaud, S., Delort, A.-M., Eyheraguibel, B., Meistertzheim, A.-L., Jacquin, J., Cheng, J., Callac, N., Odobel, C., Rabouille, S., Ghiglione, J.-F., 2018. Colonization of non-biodegradable and biodegradable plastics by marine microorganisms. Front. Microbiol. 9, 1571.

Elasri, M.O., Miller, R.V., 1999. Study of the response of a biofilm bacterial community to UV radiation. Appl. Environ. Microbiol. 65 (5), 2025-2031.

Gewert, B., Plassmann, M.M., MacLead, M., 2015. Pathways for degradation of plastic polymers floating in the marine environment. Environ. Sci.: Process. Impacts 17, 1513-1521.

Geyer, R., Jambeck, J.R., Law, K.L., 2017. Production, use, and fate of all plastics ever made. Sci. Adv. 3, 1700782.

Gilan, I., Hadar, Y., Sivan, A., 2004. Colonization, biofilm formation and biodegradation of polyethylene by a strain of Rhodococcus ruber. Appl. Microb. Cell Physiol. 65, 97-104.

Haider, T.P., Völker, C., Kramm, J., Landfester, K., Wurm, F.R., 2019. Plastics of the future? The impact of biodegradable polymers on the environment and on society. Angew. Chem. Int. Ed. 58, 50-62.

Hammer, Ø., Harper, D.A.T., Ryan, P.D., 2001. Paleontological statistics software package for education and data analysis. Palaeontol. Electron. 4 (1), 9-18.

Janda, J.M., 2014. Shewanella: a marine pathogen as an emerging cause of human disease. Clin. Microbiol. Newsl. 36 (4), 25-29. 
Karamanlioglu, M., Preziosi, R., Robson, G.D., 2017. Abiotic and biotic environmental degradation of the bioplastic polymer poly(lactic acid): a review. Polym. Degrad. Stab. 137, 122-130.

Keegan, K.P., Glass, E.M., Meyer, F., 2016. Methods in molecular biology!microbial environmental genomics (MEG)!MG-RAST, a metagenomics service for analysis of microbial community structure and function. Microb. Environ. Genom. (MEG) 207-233.

Kirstein, I.V., Wichels, A., Krohne, G., Gerdts, G., 2018. Mature biofilm communities on synthetic polymers in seawater - specific or general ? Mar. Environ. Res. 142, 147-154.

Kirstein, V.I., Kirmizia, S., Wichelsa, A., Garin-Fernandez, A., Erler, R., Löder, M., Gerdts, G., 2016. Dangerous hitchhikers? Evidence for potentially pathogenic Vibrio spp. on microplastic particles. Mar. Environ. Res. 120, 1-8.

Koziñska, A., Pekala, A., 2004. First isolation of Shewanella putrefaciens from freshwater fish - a potential new pathogen of fish. Bull. Eur. Assoc. Fish Pathol. 24 (4), 189.

Lobelle, D., Cunliffe, M., 2011. Early microbial biofilm formation on marine plastic debris. Mar. Pollut. Bull. 62, 197-200.

Mahoney, K.W., Talbert, J.N., Goddard, J.M., 2013. Effect of polyethylene glycol tether size and chemistry on the attachment of lactase to polyethylene films. J. Appl. Polym. Sci. 127 (2), 1203-1210.

Maugeri, L., Carbone, M., Fera, M.T., Irrera, G.P., Gugliandolo, C., 2004. Distribution of potentially pathogenic bacteria as free living and plankton associated in a marine coastal zone. J. Appl. Microbiol. 97, 354-361.

Morawiec, J., Pawlak, A., Slouf, M., Galeski, A., Piorkowska, E., Krasnikowa, N., 2005. Preparation and properties of compatibilized ldpe/organo-modified montmorillonite nanocomposites. Eur. Polym. J. 41, 1115-1122.

Muthuraj, R., Misra, M., Mohanty, A.K., 2015. Hydrolytic degradation of biodegradable polyesters under simulated environmental conditions. J. Appl. Polym. Sci. 132 (n/an/a).

Naranci, T., Verstichel, S., Chaganti, S.R., Morales-Gamez, L., Kenny, S.T., De Wilde, B., Padamati, R.B., O'Connor, K.E., 2018. Biodegradable plastic blends create new possibilities for end-of-life management of plastics but they are not a Panacea for plastic pollution. Environ. Sci. Technol. 52 (18), 10441-10452.

Nunes, I., Jacquiod, S., Brejnrod, A., Holm, P.E., Johansen, A., Brandt, K.K., Priemé, A. Sorensen, S.J., 2016. Coping with copper: legacy effect of copper on potential activity of soil bacteria following a century of exposure. FEMS Microb. 92, 11 (Ecol.).

Oberbeckmann, S., Osborn, A.M., Duhaime, M.B., 2016. Microbes on a bottle: substrate, season and geography influence community composition of microbes colonizing marine plastic debris. PLoS One 11, 0159289.

Paul, M.-A., Alexandre, M., Degée, P., Calberg, C., Jérôme, R., Dubois, P., 2003. Exfoliated polylactide/clay nanocomposites by in-situ coordination-insertion polymerization. Macromol. Rapid Commun. 24 (9), 561-566.

Pinto, M., Langer, T.M., Thorsten, H., Hofmann, T., Herndl, G.J., 2019. The composition of bacterial communities associated with plastic biofilms differs between different polymers and stages of biofilm succession. PLoS One 14, e0217165.

Plastics, the facts, European plastics. 2019
Rochman, C.M., Browne, M.A., Halpern, B.S., Hentschel, B., T, Hoh, E., Karapanagioti, H. K., Rios-Mendoza, L.M., Takada, H., Teh, S., Thompson, R.C., 2013a. Classify plastic waste as hazardous. Nature 494 (7436), 169-171.

Rochman, C.M., Hoh, E., Kurobe, T., Teh, S.J., 2013b. Ingested plastic transfers hazardous chemicals to fish and induces hepatic stress. Sci. Rep. 3, 3263

Roy, P.K., Titus, S., Surekha, P., Tulsi, E., Deshmukh, C., Rajagopal, C., 2008. Degradation of abiotically aged LDPE films containing pro-oxidant by bacterial consortium. Polym. Degrad. Stab. 93 (10), 1917-1922.

Rummel, C.D., Jahnke, A., Gorokhova, E., Kühnel, D., Schmitt-Jansen, M., 2017. Impacts of biofilm formation on the fate and potential effects of microplastic in the aquatic environment. Environ. Sci. Technol. Lett. 4 (7), 258-267.

Sombatsompop, N., Sungsanit, K., 2004. Structural changes of PVC in PVC/LDPE meltblends: effects of LDPE content and number of extrusions. Polym. Eng. Sci. 44 (3), 487-495.

Sudhakar, M., Trishul, A., Doble, M., Suresh Kumar, K., Syed Jahan, S., Inbakandan, D., Viduthalai, R.R., Umadevi, V.R., Sriyutha Murthy, P., Venkatesan, R., 2007. Biofouling and biodegradation of polyolefins in ocean waters. Polym. Degrad. Stab. 92, 1743-1752.

Thompson, J.R., Polz, M.F., 2006. Dynamics of Vibrio populations and their role in environmental nutrient cycling. In: Thompson, F.L., Austin, B., Swings, J. (Eds.), The Biology of Vibrios. ASM Press, Washington, DC, pp. 190-203.

Volova, T.G., Gladyshev, M.I., Trusova, M.Y., Zhila, N.O., 2007. Degradation of polyhydroxyalkanoates in eutrophic reservoir. Polym. Degrad. Stab. 92, 580-586.

Wang, X.-W., Wang, G.-X., Huang, D., Lu, B., Zhen, Z.-C., Ding, Y., Ren, Z.-L., Wang, P.-L., Zhang, W., Ji, J.-H., 2019. Degradability comparison of poly(butylene adipate terephthalate) and its composites filled with starch and calcium carbonate in different aquatic environments. J. Appl. Polym. Sci. 136, 46916.

Wang, Y., Naumann, U., Wright, S.T., Warton, D.I., 2012. Mvabund - an R package for model-based analysis of multivariate abundance data. Methods Ecol. Evol. 3, 471-474.

Weng, Y.-X., Jin, Y.-J., Meng, Q.-Y., Wang, L., Zhang, M., Wang, Y.-Z., 2013. Biodegradation behavior of poly(butylene adipoate-co-terephthalate) (PBAT), poly (lactic acid) (PLA), and their blend under soil conditions. Polym. Test. 32, 918-926.

Wilcox, C., Sebille, Van, Hardesty, E., Threat, B.D., 2015. of plastic pollution to seabirds is global, pervasive, and increasing. Proc. Natl. Acad. Sci. U.S.A. 112 (38), 11899-11904.

Xanthos, D., Walker, T.R., 2017. International policies to reduce plastic marine pollution from single-use plastics (plastic bags and microbeads): a review. Mar. Pollut. Bull. 118 (1-2), 17-26.

Yoshida, S., Hiraga, K., Takehana, T., Taniguchi, I., Yamaji, H., Maeda, Y., Toyohara, K., Miyamoto, K., Kimura, Y., Oda, K., 2016. A bacterium that degrades and assimilates poly(ethyleneterephthalate). Science 351, 1196-1199.

Zettler, E.R., Mincer, T.J., Amaral-Zettler, L.A., 2013. Life in the "plastisphere": microbial communities on plastics marine debris. Environ. Sci. Technol. 47 (13), 7137-7146.

Zhang, D.-C., Margesin, R., 2015. Marinomonas mangrovi sp. nov., isolated from mangrove sediment. Int. J. Syst. Evolut. Microbiol. 65, 1537-1541. 